\title{
Sustainable Growth Rate Model in Indonesia Manufacturing Firms
}

\author{
Vina Christina Nugroho* \\ Business School, Universitas Pelita Harapan \\ MH Thamrin Boulevard 1100, Kelapa Dua, Tangerang, Banten 15811, Indonesia \\ vina.nugroho@uph.edu
}

Received: $07^{\text {th }}$ August 2020/ Revised: $16^{\text {th }}$ November 2020/ Accepted: $23^{\text {rd }}$ November 2020

How to Cite: Nugroho, V. C (2020). Sustainable growth rate model in Indonesia manufacturing firms. The Winners, 21(2), 93-100. https://doi.org/10.21512/tw.v21i2.6614

\begin{abstract}
Regarding the importance of Sustainable Growth Rate (SGR) calculation for firms as a basic of financial decision, many previous studies had highlighted the variability of SGR calculation. The research's first objective focused on two methods of SGR calculation and figured out the determinant factors (internal and external) that affect firm's SGR. One method focused on different determinants of SGR when industry or firm specific aspects were considered. Whereas, SGR (II) focused on determinant of SGR when firms are reluctant to issue new equity. The second objective was to investigate the determinant factors towards SGR in both models. Sample for the research was public-listed manufacturing firms in Indonesia from 2011 to 2019 . The result shows that there is significant difference between the two methods, and not to mention that Return on Equity (ROE) becomes the only factor that affect SGR (in both models). The implication is due to the limited amount of time, so the research can only compare two different method of SGR.
\end{abstract}

Keywords: sustainable growth rate, manufacturing firms, return on equity

\section{INTRODUCTION}

Wealth maximization has been the core value that many academic and practitioners in corporate finance are pursuing. Proxy for wealth maximization is still being debated until today. However, the underlying assumption for wealth maximization is an increasing value of the firm or increasing value of shareholder. The word 'growth' has always occured when it comes to investigating about firm's performance to increase firm's values. Several studies have been conducted to examine growth related measures and their impact on firm's values. Growth has become a widely accepted aim in any business (Arora et al., 2018). More equity leads to potential growth, however, if the business grows too fast, there is a probability of lack equity to sustain the growth. Whereas, if it is too slow, the business could become stagnant (Hartono \& Utami, 2016). Sustainable growth is required to survive in a competitive world of business. Sustainable growth involves a situation where firm experiences growth, but assets, equity issuance, liabilities and retained earnings remains unchanged. Sustainable growth allows investors and analysts to find the maximum possible rate of growth that firm can achieve by using existing resources. Sustainable Growth Rate (SGR) calculation can help corporate managers to do financial planning efficiently as it allows managers and investors estimate whether future growth plans are realistic or not (Mamilla, 2019). Some corporate managers face the facts that unrestrained growth is inconsistent with established financial policies. Major problems that has been highlighted by (Higgins, 2015) that are financial policies or financial decisions are incompatible with their growth objectives. This SGR is the best option to mitigate this problem.

Most of corporate managers believe that higher growth rate is better, but, higher growth rate requires a huge investment in fixed assets. This can lead a problem, especially when firms are facing economic crisis. Those huge investment in fixed assets can incur higher costs and debt burdens. The concept of Sustainable Growth Rate (SGR) emerges as an insight provider to this problem (Arora et al., 2018). (Higgins, 2015), defines Sustainable Growth Rate as the maximum rate at which firm's sales can increase without depleting financial resources. SGR require careful examination of internal and external factors because SGR is used by managers in balancing their financial decision and firm's operational. Many previous studies have highlighted the variability of SGR calculation, but still based on Higgins four 
important ratios of SGR which is profit retention ratios, Net Profit Margin, Asset Turnover and Financial Leverage. The purpose of this research is comparing the two methods of SGR calculation and figure out the determinant of SGR. Fonseka, Ramos and Tian (2012) state that the one model chosen over the other should be caused by several factors: 1) When SGR is measured by continuous variables and significantly related to a wide array of financial characteristics, it leads to a different manner of various SGR estimator's; 2) The SGR is defined as a dichotomous variable of firms which are classified as either above or below zero level of the SGR (positive or negative growth). This different level of SGR may also lead to the wide arrays of commonly used financial factors that will have different impact on SGR's sign of direction (positive and negative signs); 3 ) The concern about the economic sense of SGR applicability, model should be more suitable for managers or practitioners or for academician or researchers.

The concept of SGR focuses on strategic plan whether firm's plan can be funded using the existing resources. Comparison between SGR rate with actual growth rate (sales growth) gives a clue for managers and investors the probability whether they may face cash flow problems in the future or not. The research uses SGR to evaluate each industry's performance during particular period of time. Targeting specific industry to make an investment requires special attention for investors to investigate performance by looking at their SGR. In addition to the research purpose, there will be provided some valuable information such as how SGR rate varies across industries and differentiating each industry based on their growth rates calculation using two different methods.

The research is expected to give some valuable information whether this will lead to a significant differences on the results from the two methods. Not to mention that the research would help the investors to pick industry in a rational way and objectively.

Many previous research has been conducted to investigate the importance of growth. The concept of SGR, as introduced by Babcock (1970), has been provided with a simple explanation on the behaviour of various elements. Higgins (2015) focuses on the signs of unpleasant financial condition that caused by unrestrained growth within a firm. Furthermore, Platt, Platt and Chen (1995) extended the research towards firms in financial distress by developing a formula that calculate how much growth can be achieved without external debt and maintain capital structure. By the time, Gardner, McGowan Jr \& Moeller et al. (2011) describe various calculations of SGR, while Wang et al. (2019) highlight the influence of SGR that takes into account of social, energy and environmental factors in the scope of oil and gas industry. Fonseka et al. (2012) point out that there are several models formulated by different researchers regarding SGR's calculation. They argue that some of those models can be widely and commonly used as SGR model, but the others can only be adopted in specific conditions.
For instance, Platt et al. (1995) and Escalante et al. (2009) point out the SGR model for financial distress that develops a sustainable growth challenge model for agricultural industry. This occurs to be a better indication of the importance of SGR research for academic purposes. Despite many debates among researchers towards the most appropriate commonlyused SGR model, the research uses two SGR models which are widely and commonly used by Higgins (2015) and Babcock (1970). The research has its own novelty that can be distinguished from previous research. It is the objectives to find significant differences among the two methods of calculating SGR, while many previous research use only single calculation of SGR.

Higgins (1981) assumes that the company does not issue new equity capital. He uses four important ratios as $\mathrm{SGR}=\mathrm{RR} \times \mathrm{NPM} \times \mathrm{ATO} \times \mathrm{FL}$. A simple version from those formula can be calculated by SGR $=$ ROE $\times$ b (see Table 1).

However, Arora et al. (2018) argues that nature and magnitude errors can be generated by using those formula. Therefore, in the light from his argument, this research considers this following formula for calculating SGR (I) as follow

$$
\operatorname{SGR}(\mathrm{I})=[\operatorname{ROE} \times b] /[1-(\operatorname{ROE} \times b)]
$$

Babcock (1970) argues that change in Book Value of Equity (BVE) will make an impact on the stock performance in term of capital appreciation. He believes that change of BVE is the only suitable source of fund for the firm's growth. Based on the fundamental assumption from this model, firm does not use external financing to growth. SGR can be calculated using year on year percentage change in book value of equity, so the calculaton of SGR II is provided as:

$$
\mathrm{SGR}(\mathrm{II})=\left[\mathrm{BE}_{\mathrm{t}} / \mathrm{BE}_{\mathrm{t}-1}\right]-1
$$

The major difference between those two models can be identified since SGR I focus on different determinants when the industry's or firm's specific aspect has to be considered (firm operating in same or varied industries), whereas SGR II focus on aggregate view of SGR without considering the specific factors. The underlying fundamental assumption from SGR II occurs when firm is reluctant to issue new equity (Arora et al., 2018). Beside the variation of SGR calculation, Jarvis, Mayo and Lane (1992) highlight the concept of SGR for picking up specific industries for the sake of receiving special attention and assistance from government. They find out how SGR model is affected by specific type of government's programmes. Hou and Robinson (2006) explicitly focus on the need of industry specific factors toward asset pricing model. Platt and Platt (1991) find that industry relative specifications are more accurate and stable in term of their predictive performance. Based those previous research, it seems that there has not 
Table 1 Operational Variable

\begin{tabular}{ll}
\hline \multicolumn{1}{c}{ Variable } & \multicolumn{1}{c}{ Measurement } \\
\hline Retention Ratio (RR) & Retained Earnings / Net Income \\
Net Profit Margin (NPM) & Net Income / Sales \\
Asset Turn Over (ATO) & Sales / Total Assets \\
Financial Leverage (FL) & Total Assets / Book Value of Equity \\
Return on Equity (ROE) & Net Income / Shareholder's Equity \\
Return on Assets (ROA) & Net Income / Total Assets \\
Sales Growth (SG) & Year on year growth in sales \\
Total Assets Growth (TAG) & Year on year growth in Total Assets \\
Inflation & Inflation rate derived from (data.worldbank.org) \\
Retention Rate (b) & 1- Dividen Payout Ratio \\
\hline
\end{tabular}

Source: Arora et al. (2018)

been literature review describing the variability on SGR as a result of internal and external influence for firms. Therefore, the contributions of the research are to 1) highlight two different approach to describe various determinants of SGR, and 2) examine internal and external factors towards firm's SGR.

\section{METHODS}

Panel data regression to identify the suitable formula in calculating SGR and also identify factors that influence SGR. The panel data are from public listed companies in Indonesia from 2011-2019 derived from S\&P Capital IQ plattform. Financial industry and service industry are excluded due to the differences in relative mix of tangible and intangible assets in service and industrial sector (Mayo \& Jarvis, 1992). Not to mention that sample with incomplete information or companies, in which financial data was missing, are also excluded. There are 166 companies included in the sample.

The two separate groups of hypotheses are shown in this section. The first section mentions the hypothesis for sustainable growth rates which are computed using two different approach. According to Arora et al. (2018) there is inconsistency result derived from two different calculation. On the other hand, Fonseka et al. (2012), using previous research of SGR Model by Higgins, 2015), confirmed that HSGR and VSGR models produce approximately same result in the US manufacturing company from 2000 to 2008. From those two previous research, the first hypothesis is proposed as:

Hypothesis 1: There is difference result between SGR I and SGR II

The research uses the same formula of SGR calculation as Arora et al. (2018) has done (Table 1). It also focuses on internal and external factors that may have an impact toward SGR. Arora et al. (2018) state that Net Profit Margin has a positive and significant effect towards SGR in both Model. Therefore the second hypothesis is proposed as:

Hypothesis 2: Net Profit Margin has a positive and significant effect towards SGR in both models.

Arora et al. (2018) has conducted a research in Indian Manufacturing firms from 1998 to 2014, from which this research replicates empirical model to examine the internal and external influence for SGR.

$\operatorname{SGR}(\mathrm{I})_{\mathrm{i}, \mathrm{t}}=y_{0, \mathrm{t}}+y_{1, \mathrm{t}}\left(\mathrm{RR}_{\mathrm{it}}\right)+y_{2, \mathrm{t}}\left(\mathrm{NPM}_{\mathrm{it}}\right)+y_{3, \mathrm{t}}\left(\mathrm{ATO}_{\mathrm{it}}\right)$ $+y_{4, \mathrm{t}}\left(\mathrm{FL}_{\mathrm{it}}\right)+y_{5, \mathrm{t}}\left(\mathrm{ROA}_{\mathrm{it}}\right)+y_{6, \mathrm{t}}\left(\mathrm{ROE}_{\mathrm{it}}\right)+y_{7, \mathrm{t}}\left(\mathrm{SG}_{\mathrm{it}}\right)+y_{8, \mathrm{t}}$ $\left(\mathrm{TA}_{\mathrm{it}}\right)+y_{9, \mathrm{t}}\left(\mathrm{INF}_{\mathrm{it}}\right)+\varepsilon \mathrm{Eit}$

$\mathrm{SGR}(\mathrm{II})_{\mathrm{i}, \mathrm{t}}=y_{0, \mathrm{t}}+y_{1, \mathrm{t}}\left(\mathrm{RR}_{\mathrm{it}}\right)+y_{2, \mathrm{t}}\left(\mathrm{NPM}_{\mathrm{it}}\right)+y_{3, \mathrm{t}}\left(\mathrm{ATO}_{\mathrm{it}}\right)$ $+y_{4, \mathrm{t}}\left(\mathrm{FL}_{\mathrm{it}}\right)+y_{5, \mathrm{t}}\left(\mathrm{ROA}_{\mathrm{it}}\right)+y_{6, \mathrm{t}}\left(\mathrm{ROE}_{\mathrm{it}}\right)+y_{7, \mathrm{t}}^{3, \mathrm{t}}\left(\mathrm{SG}_{\mathrm{it}}\right)+$ $y_{8, \mathrm{t}}\left(\mathrm{TAG}_{\mathrm{it}}\right)+y_{9, \mathrm{t}}\left(\mathrm{INF}_{\mathrm{it}}\right)+\varepsilon \mathrm{it}$

\section{RESULTS AND DISCUSSIONS}

Prior calculation is conducted to analyse the behaviour pattern of internal factors within SGR's behaviour. Table 2 shows each portfolio of variable across stocks. Means are calculated of the average over period 2011 to 2019. Data is divided by the value of SGR from the lowest to highest.

Portfolio from SGR (I) could not capture any pattern due to random values which are hard to predict and conclude. Portfolio from SGR (II) indicate that higher SGR lead to higher NPM, higher ROE and higher ROA. This pattern is actually predictable and in line with the definition of SGR. Firm with high SGR is a firm with capability to maximize growth using existing resources. Arora et al. (2018), having conducted research in Indian Manufacturing Firms, also show the same results as Panel B. Sales growth in most of the portfolio exceeds sustainable growth 
rate, which indicate a potential problem as Arora et al. (2018) has encountered.

The descriptive analysis for each specific industry is provided based on Table 3 to know the performance of SGR in each industry.

As Table 3 shows descriptive statistics of
SGR (I), it is found that Textile industry has highest SGR and building construction has lowest SGR. At the other hand, different result also appears in the data. Descriptive statistics of SGR (II), shows that miscellaneous industry has highest SGR, whereas oil and gas has the lowest SGR.

Table 2 Behaviour of Proposed Determinants (Internal) of Sustainable Growth Rate

Panel A. Behaviour of Proposed Determinants (Internal) of SGR (I)

\begin{tabular}{cccccccccc}
\hline & SGR1 & RR & NPM & ATO & FL & ROA & ROE & SG & TAG \\
\hline Low & $-1,187$ & 3,464 & 0,132 & 0,049 & 3,049 & 0,037 & 0,060 & 0,110 & 0,196 \\
2 & $-0,674$ & 3,051 & $-0,027$ & 0,051 & 1,657 & 0,007 & $-0,018$ & 0,679 & 0,040 \\
3 & $-0,605$ & $-0,933$ & 0,016 & 0,033 & 1,229 & $-0,007$ & 0,002 & 0,067 & $-0,026$ \\
4 & $-0,546$ & $-16,883$ & $-0,012$ & 0,025 & 2,390 & 0,024 & $-0,012$ & 0,006 & 0,032 \\
5 & $-0,479$ & 6,602 & $-0,001$ & 0,181 & 1,246 & $-0,003$ & $-0,009$ & 2,002 & 0,006 \\
6 & $-0,375$ & $-13,815$ & $-0,021$ & 0,036 & 0,680 & $-0,004$ & $-0,003$ & 0,174 & $-0,143$ \\
7 & $-0,329$ & 5,371 & $-0,001$ & 0,061 & 2,044 & 0,007 & $-0,005$ & 0,062 & 0,345 \\
8 & $-0,256$ & $-14,798$ & $-0,003$ & 0,032 & 2,759 & 0,017 & $-0,003$ & $-0,109$ & 0,061 \\
9 & $-0,180$ & $-2,334$ & 0,000 & 0,063 & 1,610 & 0,012 & $-0,002$ & 0,181 & $-0,051$ \\
High & 6,763 & 3,431 & 0,015 & 0,062 & 2,319 & 0,012 & 0,002 & 0,083 & 0,586 \\
\hline
\end{tabular}

Panel B. Behaviour of Proposed Determinants (Internal) of SGR (II)

\begin{tabular}{cccccccccc}
\hline & SGR2 & RR & NPM & ATO & FL & ROE & ROA & SG & TAG \\
\hline Low & $-0,204$ & 3,202 & 0,000 & 0,083 & 3,422 & $-0,072$ & 0,005 & 0,188 & 0,079 \\
2 & 0,007 & 1,885 & 0,068 & 0,046 & 2,250 & 0,027 & 0,028 & $-0,028$ & 0,104 \\
3 & 0,012 & $-5,444$ & 0,014 & 0,046 & 2,406 & 0,019 & 0,017 & 0,099 & 0,022 \\
4 & 0,017 & 9,888 & 0,042 & 0,028 & 2,594 & 0,030 & 0,031 & 0,075 & 0,059 \\
5 & 0,021 & 1,580 & 0,049 & 0,029 & 2,597 & 0,041 & 0,037 & 0,022 & 0,057 \\
6 & 0,025 & $-3,114$ & 0,028 & 0,032 & 2,376 & 0,028 & 0,026 & 0,103 & 0,035 \\
7 & 0,030 & 3,933 & 0,058 & 0,037 & 2,419 & 0,080 & 0,048 & $-0,020$ & 0,060 \\
8 & 0,034 & 2,525 & 0,083 & 0,043 & 2,058 & 0,057 & 0,038 & $-0,033$ & 0,082 \\
9 & 0,038 & 4,547 & 0,048 & 0,042 & 2,046 & 0,039 & 0,027 & 0,140 & 0,071 \\
High & 0,219 & 3,563 & 0,219 & 0,030 & 2,635 & 0,143 & 0,058 & 0,082 & 0,334 \\
\hline
\end{tabular}

Source: Data Processing (2020)

Table 3 Descriptive Statistics for SGR (I) on Specific Industries

\begin{tabular}{lccccc}
\hline \multicolumn{1}{c}{ Industry } & $\begin{array}{c}\text { Number of } \\
\text { Observation }\end{array}$ & Mean & Std. Deviation & Min. & Max. \\
\hline Agriculture & 54 & $-0,988$ & $-0,090$ & $-1,240$ & $-0,540$ \\
Automotive \& Airline & 108 & $-0,578$ & 2,864 & $-5,716$ & 21,222 \\
Building Construction & 81 & $-1,370$ & 2,515 & $-22,276$ & 1,967 \\
Coal \& Consumable Fuel & 63 & $-0,997$ & 0,108 & $-1,574$ & $-0,690$ \\
Electrical \& Software & 72 & $-0,421$ & 5,162 & $-4,496$ & 42,478 \\
F\&B & 135 & $-0,858$ & 5,809 & $-33,258$ & 57,823 \\
Miscellaneous & 144 & $-0,669$ & 2,113 & $-2,402$ & 15,129 \\
Logistics & 81 & $-1,017$ & 0,356 & $-2,360$ & 0,934 \\
Oil \& Gas & 126 & $-1,284$ & 2,092 & $-23,727$ & 1,173 \\
Real Estate & 198 & $-0,721$ & 2,072 & $-9,130$ & 12,157 \\
\hline
\end{tabular}


Table 3 Descriptive Statistics for SGR (I) on Specific Industries (Continued)

\begin{tabular}{lccccc}
\hline \multicolumn{1}{c}{ Industry } & $\begin{array}{c}\text { Number of } \\
\text { Observation }\end{array}$ & Mean & Std. Deviation & Min. & Max. \\
\hline Steel \& Mining, Chemical & 117 & $-1,026$ & 1,072 & $-9,403$ & 1,857 \\
Tellecomunication, TV \& Broadcasting & 126 & $-1,053$ & 0,931 & $-9,849$ & 0,291 \\
Textile & 63 & $-0,202$ & 5,392 & $-9,620$ & 40,666 \\
\hline
\end{tabular}

Source: Data Processing (2020)

Table 4 Descriptive Statistics for SGR (II) on Specific Industries

\begin{tabular}{lccccc}
\hline \multicolumn{1}{c}{ Industry } & $\begin{array}{c}\text { Number of } \\
\text { Observation }\end{array}$ & Mean & Std. Deviation & Min. & Max. \\
\hline Agriculture & 54 & 0,078 & 0,473 & $-1,260$ & 2,118 \\
Automotive \& Airline & 108 & 0,046 & 0,610 & $-2,782$ & 3,796 \\
Building Construction & 153 & 0,158 & 0,615 & $-2,798$ & 5,053 \\
Coal \& Consumable Fuel & 63 & 0,009 & 0,588 & $-1,000$ & 2,866 \\
Electrical \& Software & 72 & 0,144 & 0,345 & $-1,000$ & 1,476 \\
F\&B & 135 & 0,131 & 1,518 & $-10,648$ & 11,973 \\
Miscellaneous & 144 & 0,234 & 3,230 & $-3,241$ & 38 \\
Logistics & 81 & $-0,103$ & 0,325 & $-1,000$ & 0,220 \\
Oil \& Gas & 126 & $-0,190$ & 1,830 & $-20,073$ & 1,125 \\
Real Estate & 198 & 0,132 & 0,620 & $-1,220$ & 8,246 \\
Steel \& Mining, Chemical & 117 & 0,001 & 0,259 & $-1,000$ & 1,054 \\
Tellecomunication, TV \& Broadcasting & 126 & 0,102 & 1,338 & $-10,884$ & 7,066 \\
Textile & 63 & $-0,011$ & 0,670 & $-3,346$ & 2,210 \\
\hline
\end{tabular}

Source: Data Processing (2020)

Inconsistent results from the calculations in Table 4 lead us to investigate the degree of correlation between two models of SGR. Table 5 shows that correlation between SGR (I) and SGR (II) is considered quite low $(0,019)$. Not surprisingly, portfolio calculation in Table 4 shows different results.

Table 5 Correlation Matrix between SGR (I) and SGR (II)

\begin{tabular}{ccc}
\hline & SGR (I) & SGR (II) \\
\hline SGR (I) & 1 & \\
SGR (II) & 0,019 & 1 \\
\hline
\end{tabular}

Source: Data Processing (2020)

Along with that correlation, Table 6 shows the correlation matrix for all variables (independent, dependent and control variable). The collinearity table is used to look at reciprocal linkages between one variable and other variables. The value of collinearity among free variables is expected to be no more than one. From Table 6, the correlation between each variable with SGR in both methods can be predicted.
Consistent result can be seen from variable RR, NPM, ROE, and FL. Variable profit RR, NPM and ROE have positive correlation with SGR in both models. This result is consistent with previous result in Table 2 Panel B. Firm with higher SGR shows higher NPM resulting in higher capability to manage profit retention ratio and efficiently manage their equity. Whereas, financial leverage has negative correlation with both model. It means, firm with high SGR should have a low financial leverage and vice versa.

By using the formula in equation (1) and (2), the research provides analysis on various determinants that can affect SGR in two models using panel data regression. Inflation, in this case, can be considered as macroeconomic factors since macroeconomic environment can influence firm's financial decision making (Arora et al., 2018). Before regression, F-test and Hausman test are conducted to decide the type of model used to analyse the determinants of SGR. Table 7 shows that p-value from SGR (I) is below 0,05 , so model of SGR (I) depicts fixed effect model. On the other hand, $p$-value from SGR (II) is above 0,05 , so SGR (II) model can be regarded as random effect model. Nevertheless, the treatment for classic assumption test for both models should be different. The initial tests that have to be conducted for each 
model are heteroscedasticity test, the autocorrelation test using the Wooldridge Test (WT) method, and the cross-dependence test using Pesaran's test. The balanced panel data is used so that it can be tested using Pesaran's test. In this research, the autocorrelation problem is solved simultaneously with the heteroscedasticity and cross-dependence problem. Handling for heteroscedasticity, autocorrelation, and cross-dependence problems are conducted simultaneously, using cluster-robust regression standard errors. The regression results generated using this method have eliminated heteroscedasticity, autocorrelation, and cross-dependence on the model.

The regression results can be divided into two models. Model in equation (1) where SGR (I) as dependent variable and model in equation (2) where

Table 6 Correlation Matrix for All Variables

\begin{tabular}{|c|c|c|c|c|c|c|c|c|c|c|c|}
\hline & SGR 2 & SGR1 & ATO & SG & TAG & RR & NPM & ROE & ROA & FL & Infl. \\
\hline SGR2 & 1,00 & & & & & & & & & & \\
\hline SGR1 & 0,01 & 1,00 & & & & & & & & & \\
\hline ATO & $-0,10$ & 0,01 & 1,00 & & & & & & & & \\
\hline $\mathrm{SG}$ & $-0,02$ & 0,02 & 0,14 & 1,00 & & & & & & & \\
\hline TAG & 0,04 & $-0,00$ & $-0,24$ & $-0,06$ & 1,00 & & & & & & \\
\hline $\mathrm{RR}$ & 0,01 & 0,00 & $-0,00$ & $-0,00$ & $-0,04$ & 1,00 & & & & & \\
\hline NPM & 0,23 & 0,00 & $-0,10$ & 0,01 & 0,00 & 0,02 & 1,00 & & & & \\
\hline ROE & 0,55 & 0,00 & $-0,12$ & $-0,06$ & 0,02 & 0,00 & 0,38 & 1,00 & & & \\
\hline ROA & 0,41 & $-0,00$ & $-0,18$ & $-0,09$ & 0,00 & $-0,00$ & 0,45 & 0,68 & 1,00 & & \\
\hline FL & $-0,19$ & $-0,01$ & 0,06 & 0,01 & 0,00 & $-0,11$ & $-0,06$ & $-0,23$ & $-0,11$ & 1,00 & \\
\hline Infl. & 0,01 & 0,02 & $-0,03$ & 0,04 & $-0,02$ & $-0,01$ & $-0,01$ & $-0,02$ & $-0,02$ & $-0,03$ & 1,00 \\
\hline
\end{tabular}

Source: Data Processing (2020)

Table 7 Applicability of Model

\begin{tabular}{cc}
\hline Dependent Variabel & Probability $>$ Chi-Square \\
\hline SGR (I) & 0,0172 \\
SGR (II) & 0,0743 \\
\hline
\end{tabular}

Source: Data Processing (2020)

Table 8 Regression Result

\begin{tabular}{lcccc}
\hline \multirow{2}{*}{ Variable } & \multicolumn{2}{c}{ SGR (I) } & \multicolumn{2}{c}{ SGR (II) } \\
\cline { 2 - 5 } & Sign of Coefficient & P Value & Coefficient & P Value \\
\hline ATO & - & 0,697 & + & 0,539 \\
ROA & - & 0,350 & + & 0,939 \\
SG & - & $0,020^{*}$ & + & 0,633 \\
TAG & + & 0,896 & - & 0,643 \\
RR & - & $0,042^{*}$ & + & 0,542 \\
NPM & - & 0,639 & + & 0,107 \\
FL & - & 0,160 & - & 0,052 \\
ROE & - & $0,041^{*}$ & + & $0,000^{*}$ \\
Inflation & + & 0,080 & + & 0,333 \\
Prob. F & 0,0000 & Prof F & 0,0000 & \\
R squared & 0,0062 & Wald Chi2 & 36,89 & \\
\hline
\end{tabular}

Source: Data Processing (2020) 
Table 9 Descriptive Statistics All Variables

\begin{tabular}{|c|c|c|c|c|c|}
\hline Variable & $\begin{array}{l}\text { Number of } \\
\text { Observation }\end{array}$ & Mean & Std. Deviation & Min. & Max. \\
\hline SGR (I) & 1494 & $-0,936$ & 0,979 & $-4,460$ & 6,352 \\
\hline SGR (II) & 1494 & 0,045 & 0,277 & $-0,666$ & 0,678 \\
\hline ATO & 1494 & 0,049 & 0,186 & $-2,849$ & 2,189 \\
\hline SG & 1494 & 0,114 & 0,779 & $-3,566$ & 15,508 \\
\hline TAG & 1494 & 0,211 & 2,525 & $-0,947$ & 89,388 \\
\hline RR & 1494 & 3,241 & 12,099 & $-31,107$ & 31,551 \\
\hline NPM & 1494 & 0,120 & 0,296 & $-0,172$ & 1,144 \\
\hline ROE & 1494 & 0,054 & 0,171 & $-0,391$ & 0,351 \\
\hline ROA & 1494 & 0,036 & 0,044 & $-0,046$ & 0,126 \\
\hline FL & 1494 & 2,879 & 2,003 & 1,040 & 8,854 \\
\hline Inflation & 1494 & 0,047 & 0,013 & 0,030 & 0,064 \\
\hline
\end{tabular}

Source: Data Processing (2020)

SGR (II) as dependent variable in model 2.

Variable ATO, ROA, SG, TAG, RR, NPM, FL and ROE can be regarded as internal factor, whereas, inflation is the external factor. Based on descriptive statistics on specific industries (Table $3 \& 4$ ), portfolio of proposed determinants (Table 2 panel A \& B) and the regression result (Table 8 ), it can be concluded that SGR calculations from two different approach lead to an opposite or unsimilar result. This result contradicts with previous research by Arora et al. (2018) in India Manufacturing firm from 1998 to 2014. Even though their research shows inconsistent result from both models, both patterns of proposed determinants, descriptive statistics and coefficient from regression result show the similar pattern and same direction from both models. This happens due to high correlation matrix among two different SGR on their research. Meanwhile, in this research, correlation matrix between SGR (I) and SGR (II) is quite low $(0,019)$. Thus, with this low correlation from both dependent variable, it is not a question that it leads to contradict result from all of those calculations. It is found out that first hypothesis is not rejected.

Each year, from 2011 to 2019, SGR (I) and SGR (II) are regressed against different determinants. As a result, only ROE significantly influence on both SGR models, but the coefficient from both model contradicts towards each other. Therefore from SGR (I) model, ROE negatively affect SGR, whereas from SGR (II), ROE positively affect SGR. From those both definition of SGR and ROE, it is considered not a surprise that ROE significantly affects SGR (regardless negative or positive sign) since ROE is considered as the capability of firm to effectively manage company's assets to create profits. This in line the definition of SGR. Companies that manage their assets effectively are mostly capable of maximizing sales without increasing cost. However, a negative sign is also possible if a firm increases their income and sales without capability of managing the usage of financial resources. In short, their ROE can be high, but their SRG will decrease.

ATO, ROA, TAG and FL give no significant effect toward SGR in both models. This results also supported by Arora et al. (2018) and Wang et al. (2019) pointing out that ROE has positive and significant impacts toward SGR. Exceedingly high ROA, ATO and TAG can indicated the inefficient use of assets.

In some previous research, NPM positively gives significant effect towards SGR in both models. While in this research, there is no significant effect of NPM towards SGR. Therefore, it can be stated that the second hyphotesis is rejected. Inflation seems has no impact on both models, which is in line with previous research by Arora et al. (2018) and Higgins (2015). Sales growth has a significant negative impact towards SGR (I), but no impact on SGR (II). This negative relationship between SG and SGR occurs because firm may get an increased sales without being capable of managing or cutting their costs. This result contradicts Kijewska (2016), which states that if growth exceeds the financial resources necessary to maintain their SGR, the company have to seek additional financing either through retained earnings (internal financing) or through issuing new shares or borrowing (external financing). This condition has not happened in Indonesia since many firms in Indonesia are considered incapable of maintaining sales growth meanwhile balancing their SGR. Profit Retention Ratio or RR seems to have negative significant impact towards SGR (I). This result in line with Higgins (2015) pointing out that profit retention ratio affects SGR.

\section{CONCLUSIONS}

In aiming to address the variations of SGR calculations, the result of the research shows that there is an inconsistent result between two methods 
occurring in public listed manufacturing firms in Indonesia between 2011 until 2019, excluding service industry and financial institutions. The research concludes that SGR calculations from two different approach lead to a totally different results due to the severely correlation matrix between SGR (I) and SGR (II).

Beside that, internal and external factors that can be the determinant factors of SGR is ROE for both models. From SGR (I) model, ROE negatively affect SGR. whereas, from SGR (II) ROE positively affect SGR. Accordingly, ROE occurs to give significant effects towards SGR, regardless the negative or positive sign, since ROE is considered as the capability of firm to effectively manage company's assets to generate profits. The ability to effectively manage assets will make companies capable of maximizing sales without increasing cost. However, high ROE might have potential to decrease SRG if a firm increases income and sales but neglects to manage the usage of financial resources.

The limitation of the research comes from the low correlation of SGR models, which makes its result confusing for managers and researchers. To mitigate this confusion, managers and researches should have managed to know the objectives of SGR they want to focus on. SGR (I) promises to provide information about different determinants when industry or firm specific aspects are considered. Whereas, SGR (II) promises to provide an aggregate view of SGR, when firms are reluctant to issue new equity.

\section{REFERENCES}

Arora, L., Kumar, S., \& Verma, P. (2018). The anatomy of sustainable growth rate of Indian manufacturing firms. Global Business Review, 19(4), 1050-1071. https://doi.org/10.1177/0972150918773002.

Babcock, G. C. (1970). The concept of sustainable growth. Financial Analysts Journal, 26(3), 108-114. https:// doi.org/10.2469/faj.v26.n3.108.

Escalante, C. L., Turvey, C. G., \& Barry, P. J. (2009). Farm business decisions and the sustainable growth challenge paradigm. Agricultural Finance Review, 69(2), 228-247. https://doi. org/10.1108/00021460910978706.

Fonseka, M. M., Ramos, C. G., \& Tian, G. L. (2012). The most appropriate sustainable growth rate model for managers and researchers. Journal of Applied Business Research, 28(3), 481-500. https://doi. org/10.19030/jabr.v28i3.6963.
Gardner, J. C., McGowan Jr., C. B., \& Moeller S. E. (2011). Using accounting information for financial planning and forecasting: An application of the sustainable growth model using Cola-Cola. Journal of Business Case Studies, 7(5), 9-16. https://doi.org/10.19030/ jbcs.v7i5.5599.

Hartono, G. C. \& Utami, S. R. (2016). The comparison of sustainable growth rate, firm's performance and value among the firms in Sri Kehati Index and IDX30 Index in Indonesia Stock Exchange. International Journal of Advanced Research in Management and Social Sciences, 5(5), 68-81. http://www.garph. co.uk/IJARMSS/May2016/7.pdf.

Higgins, R. C. (1981). Sustainable growth under inflation. Financial Management, 10(4), 36. https://doi. org/10.2307/3665217.

Higgins, R. C. (2015). Much growth can firm afford? Journal Financial Management, 6(3), 7-16.

Hou, K. \& Robinson, D. T. (2006). Industry concentration and average stock returns. The Journal of the American Finance Association, 61(4), 1927-1956. https://doi.org/10.1111/j.1540-6261.2006.00893.x.

Jarvis, L. P., Mayo, E. J., \& Lane, P. M. (1992). Picking winners: Solving an industrial policy problem with a sustainable growth model. International Marketing Review, 9(1), 19-31. https://doi. org/10.1108/02651339210009252.

Kijewska, A. (2016). Conditions for sustainable growth (SGR) for companies from metallurgy and mining sector in Poland. Metalurgija, 55(1), 139-142. https://hrcak.srce.hr/141856.

Mamilla, R. (2019). A study on sustainable growth rate for firm survival. Strategic Change, 28(4), 273-277. https://doi.org/10.1002/jsc.2269.

Mayo, E. J. \& Jarvis, L. P. (1992). Excessive growth in the service firm: A strategic marketing planning challenge. Journal of Services Marketing, 6(2), 5-14. https://doi.org/10.1108/08876049210035791.

Platt, H. D. \& Platt, M. B. (1991). A note on the use of industry-relative ratios in bankruptcy prediction. Journal of Banking and Finance, 15(6), 1183-1194. https://doi.org/10.1016/0378-4266(91)90057-S.

Platt, H. D., Platt, M. B., \& Chen, G. (1995). Sustainable growth rate of firms in financial distress. Journal of Economics and Finance, 19(2), 147-151. https://doi. org/10.1007/BF02920515.

Wang, Z., Kleiner, G., Bragina, Z., Denisov, A,. \& Steblyanskaya, A. (2019). Russian and Chinese natural gas industries: Perspectives on sustainable growth. International Journal of Public Administration, 42(15-16), 1381-1394. https://doi.or g/10.1080/01900692.2019.1645692. 